\title{
Effect of medium-pressure UV-lamp treatment on disinfection by-products in chlorinated seawater swimming pool waters
}

Cheema, Waqas Akram; Manasfi, Tarek; Kaarsholm, Kamilla Marie Speht; Andersen, Henrik Rasmus; Boudenne, Jean-Luc

Published in:

Science of the Total Environment

Link to article, DOI:

10.1016/j.scitotenv.2017.05.008

Publication date:

2017

Document Version

Peer reviewed version

Link back to DTU Orbit

Citation (APA):

Cheema, W. A., Manasfi, T., Kaarsholm, K. M. S., Andersen, H. R., \& Boudenne, J-L. (2017). Effect of mediumpressure UV-lamp treatment on disinfection by-products in chlorinated seawater swimming pool waters. Science of the Total Environment, 599-600, 910-917. https://doi.org/10.1016/j.scitotenv.2017.05.008

\section{General rights}

Copyright and moral rights for the publications made accessible in the public portal are retained by the authors and/or other copyright owners and it is a condition of accessing publications that users recognise and abide by the legal requirements associated with these rights.

- Users may download and print one copy of any publication from the public portal for the purpose of private study or research.

- You may not further distribute the material or use it for any profit-making activity or commercial gain

- You may freely distribute the URL identifying the publication in the public portal 


\section{Effect of medium-pressure UV-lamp treatment on disinfection by- products in chlorinated seawater swimming pool waters}

Waqas A. Cheema ${ }^{1,2}$, Tarek Manasfi ${ }^{3}$, Kamilla M. S. Kaarsholm ${ }^{1}$, Henrik R. Andersen ${ }^{1}$, JeanLuc Boudenne ${ }^{3 *}$

${ }^{1}$ Technical University of Denmark, Bygning 115, Bygningstorvet, 2800 Kongens Lyngby, Denmark

${ }^{2}$ National University of Sciences \& Technology, H-12, Islamabad 44000, Pakistan

${ }^{3}$ Aix Marseille Université, CNRS, LCE UMR 7376, 13331 Marseille, France

*Corresponding email: jean-luc.boudenne@univ-amu.fr
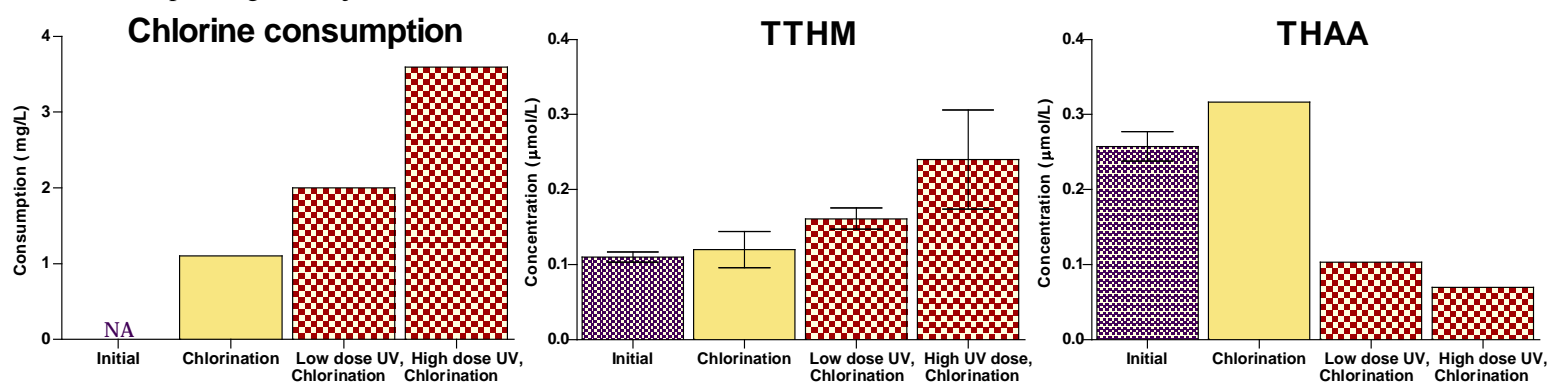

\section{Highlights}

- UV treatment increases the reactivity of seawater pool water to chlorine

- UV treatment reduces haloacetic acid concentrations after re-chlorination

- Post-UV chlorination increases trihalomethane and haloacetonitrile concentrations

- An increase in concentrations predicts higher toxicity after single UV treatment and chlorination

Abstract Several brominated disinfection by-products (DBPs) are formed in chlorinated seawater pools, due to the high concentration of bromide in seawater. UV irradiation is increasingly employed in freshwater pools, because UV treatment photodegrades harmful chloramines. However, in freshwater pools it has been reported that post-UV chlorination promotes the formation of other DBPs. To date, UV-based processes have not been investigated for DBPs in seawater pools. In this study, the effects of UV, followed by chlorination, on the concentration of three groups of DBPs were investigated in laboratory batch experiments using a medium-pressure UV lamp. Chlorine consumption increased following post-UV chlorination, most likely because UV irradiation degraded organic matter in the pool samples to more chlorine-reactive organic matter. Haloacetic acid (HAA) concentrations decreased significantly, due to photo-degradation, but the concentrations of trihalomethanes (THMs) and haloacetonitriles (HANs) increased with post-UV chlorination. Bromine incorporation in HAAs was significantly higher in the control samples chlorinated without UV irradiation but decreased significantly with UV treatment. Bromine incorporation was promoted in THM and HAN after UV and chlorine treatment. Overall, the accumulated bromine incorporation level in DBPs remained essentially unchanged in comparison with the control samples. Toxicity estimates increased with single-dose UV and chlorination, mainly due to increased HAN concentrations. However, brominated HANs are known in the literature to degrade following further UV treatment.

Keywords: trihalomethane, haloacetonitrile, haloacetic acid, post-UV chlorination, chlorine reactivity 


\section{Introduction}

The use of seawater in swimming pools was first developed for therapeutic purposes to treat sore throats, digestive problems, rheumatic arthritis, musculoskeletal injury, development disorders in children, respiratory problems (asthma and bronchitis), endocrine imbalances and skin diseases (e.g. psoriasis) (Charlier and Chaineux, 2009; Shani et al., 1995). This practice, called 'thalassotherapy', was defined by the French Medical Academy in 1960 as being the use of seawater, seaweed, sea mud or other sea resources and/or the marine climate for the purpose of medical treatment with a medicinal effect and is today largely present in Western (Great Britain, France, Germany, Spain) and Eastern Europe and along the Atlantic Ocean, Channel, Mediterranean Sea, Baltic Sea and Black Sea coasts (Crecente et al., 2012). Nowadays, seawater swimming pools are found not only in thalassotherapy centres but also in various (health) tourism and leisure sites worldwide (hotels, campsites, aquatic centres) located near to the coast (Lee and Lee, 2015; Wyer et al., 2012) or in pools and hot tubs on ships (WHO, 2006). Among the natural constituents of seawater, high levels of bromide $\left(\mathrm{Br}^{-}\right)$may be problematic, mainly when chlorination is applied to disinfect such waters. The average level of bromide in the sea is around $67 \mathrm{mg} / \mathrm{L}$ (Summerhayes and Thorpe, 1996), with levels varying from $15 \mathrm{mg} / \mathrm{L}$ in the Baltic Sea (Feistel et al., 2009) to $85 \mathrm{mg} / \mathrm{L}$ in the Mediterranean Sea and up to $5.2 \mathrm{~g} / \mathrm{L}$ in the exceptional case of the Dead Sea (Salameh et al., 2016)

Currently, chlorine is used as a disinfectant in swimming pools. However, chlorine reacts with organic and inorganic matter present in pool water and forms disinfection by-products ${ }^{1}$ (DBPs), which results in negative health effects such as irritations (eye, skin, nose and throat) (Guglielmina et al., 2010), bladder cancer (Villanueva et al., 2007) and reproductive anomalies (Hinckley et al., 2005). Furthermore, some DBPs are reported to have genotoxic and carcinogenic effects (Richardson et al., 2007). The most commonly known DBPs reported in swimming pool water are haloamines, trihalomethanes (THMs), haloacetic acids (HAAs) and haloacetonitriles (HANs) (Chowdhury et al., 2014; Manasfi et al., 2017a). However, less frequently reported and unregulated groups are halodiacids, haloaldehydes, haloketones, haloamides, halophenols, halobenzoquinones and N-nitrosamines (Richardson et al., 2010; Teo et al., 2015; Wang et al., 2013).

In chlorinated seawater pools, bromine is the most prevalent disinfectant and oxidant, as bromide ions react with chlorine to form hypobromous acid (Bougeard et al., 2010; Ged and Boyer, 2014; Wang et al., 2009). These pools are expected to have a high content of bromide and are likely to generate more brominated DBPs (Manasfi et al., 2016; Parinet et al., 2012). Furthermore, it is also known that brominated DBPs are more toxic than the chlorinated DBP (Manasfi et al., 2017b; Muellner et al., 2007; Plewa et al., 2008).

An established method employed to reduce combined chlorine in swimming pool water is direct photolysis by UV (Hansen et al., 2013a). The combined application of UV and chlorination provides opportunities for the formation of hydroxyl radicals as reactive intermediates (Feng et al., 2007). However, reaction pathways promote the formation of some DBPs with UV, followed by chlorination. Spiliotopoulou et al. (2015) described that DBPs are only formed in secondary reactions after chlorine addition during the post-UV chlorination treatment of freshwater pools. Cimetiere and De Laat (Cimetiere and De Laat, 2014) also reported increased the formation of some DBPs with UV treatment followed by chlorination in freshwater pools during the post-chlorination step. However, no data have been reported for reaction pathways leading to an increase in the formation of THMs and some other DBPs in seawater. Liviac et al. (2010) and Plewa et al. (2012) reported UV treatment for the reduction of genotoxicity and cytotoxicity in chlorinated swimming pool water and drinking water treatment systems. Furthermore, several studies have reported that mediumpressure UV lamps are more efficient than low pressure UV lamps for the photo-degradation of THMs (Kristensen et al., 2010; Zare Afifi and Blatchley, 2016).

\footnotetext{
${ }^{1}$ Abbreviations.

DBP, disinfection by-products.

HAA, haloacetic acids.

HAN, haloacetonitriles.

THM, trihalomethanes.

TOC, total organic carbon.
} 
Water characteristics in seawater pools can influence DBP formation and result in the formation of different DBPs than those found in freshwater pools. Furthermore, the higher $\mathrm{pH}$ of seawater pools than freshwater pools will also have an effect on DBP formation (Hansen et al., 2012b).

Therefore, the effect of UV treatment followed by chlorination on DBP formation was studied using laboratory experiments. Water from three different indoor chlorinated seawater pools was exposed to light from a standard medium-pressure UV lamp, followed by chlorination. Three groups of DBPs were investigated, namely THMs, HANs and HAAs. The DBP level measured after post-UV chlorination was compared to a dark control sample which was not subjected to UV exposure. Bromine substitution was investigated to analyse its effects on the formation of DBPs. Finally, overall cytotoxicity and genotoxicity were estimated for the toxic potency of compounds, before and after treatment.

\section{Material and method}

\subsection{Pool water}

\subsubsection{Sample collection}

This study included samples from three indoor seawater swimming pools in two thalassotherapy establishments located in the Cote d'Azur region in south-eastern France. The first establishment had an indoor pool (pool-1) filled with seawater, while the second establishment had two indoor pools (pool-2, pool3) filled with seawater. These seawater pools were filled with water originating from the Mediterranean Sea. The disinfection treatment involved the automatically controlled addition of sodium hypochlorite to maintain a constant level of free residual chlorine equivalents. These pools were equipped with sand filters to remove particulars and pollutants. Sampling was undertaken during March 2016. Physicochemical parameters were measured on-site while the samples were collected in 2-litre amber glass bottles and kept at $4^{\circ} \mathrm{C}$ until treated the same day.

\subsubsection{Water quality parameters}

Parameters including pH, conductivity and temperature were determined on-site, using a multi-electrode multimeter (WTW Multiline P4 multimeter, Weilheim, Germany). Residual chlorine and total chlorine were measured on-site via the colorimetric DPD method, using a spectrophotometer (AQUALYTIC-AL 800, Germany), and total organic carbon (TOC) was measured by catalytic oxidation at a high temperature (Multi N/C 2100, Analytic Jena, Germany).

\subsection{Disinfection by-product analysis}

Samples were extracted by liquid-liquid extraction (LLE) with methyl tert-butyl ether (MTBE) of Chromosolv, HPLC grade (Sigma-Aldrich, Germany) and analysed by gas chromatography coupled to an electron capture detector (GC-ECD) (Perkin Elmer Clarus 580 system, Norwalk, CT, USA). The analysis of THMs and HANs was conducted according to U.S.EPA 551.1 (Munch, D.J., Hautman, 1995) along with a number of modifications as described previously by Manasfi et al. (2016) and detailed description can be found in supporting information (Section 3.1, SI). To measure HAAs, samples were treated and analysed based on U.S.EPA 552.3 (Domino et al., 2003), again along with slight modifications as described previously by Manasfi et al. (2016) and detailed description can be found in supporting information (Section 3.2, SI). Sample aliquots $(50 \mathrm{~mL}$ ) were adjusted to $\mathrm{pH} 0.5$ or less, by adding sulphuric acid (analytical grade reagent, Fisher Scientific, UK), and then extracted with MTBE (5 mL). Next, the organic phase containing the HAAs was treated with acidified methanol at $50^{\circ} \mathrm{C}$ for $2 \mathrm{~h}$ to form the methyl ester derivatives of HAAs. The derivatised HAAs were analysed with GC-ECD. The limits of quantification (LOQ) were $0.2 \mu \mathrm{g} / \mathrm{L}$ for dibromochloromethane, bromoform, dichloroacetonitrile and dibromoacetonitrile; $0.3 \mu \mathrm{g} / \mathrm{L}$ for bromodichloromethane, trichloroacetonitrile and bromochloroacetonitrile; $0.5 \mu \mathrm{g} / \mathrm{L}$ for trichloroacetic acid, bromochloroacetic acid, dibromoacetic acid, dibromochloroacetic acid and dichloroacetic acid; $0.6 \mu \mathrm{g} / \mathrm{L}$ for bromodichloroacetic acid; $0.7 \mu \mathrm{g} / \mathrm{L}$ for dichloroacetic acid; $0.8 \mu \mathrm{g} / \mathrm{L}$ for chloroform and $1.0 \mu \mathrm{g} / \mathrm{L}$ for tribromoacetic acid, monochloroacetic acid and monobromoacetic acid. 


\subsection{UV treatment}

Batch experiments were conducted by using a thermostatically controlled cylindrical reactor with a standard medium-pressure UV lamp ( $\mathrm{P}=700 \mathrm{~W}$, Peschl Ultraviolet) further details about reactor layout and the lamps spectral emission can be found in supporting information (Fig S1,S2). In this work, the UV dose was determined according to the method described by Hansen et al. (2013a). A UV exposure cylindrical reactor setup was correlated to the real flow-through system on the pool by using combined chlorine as an actinometer. A UV system requires $1.0 \mathrm{kWh} / \mathrm{m}^{3}$ to remove $90 \%$ of combined chlorine and $0.61 \mathrm{kWh} / \mathrm{m}^{3}$ to remove monochloramine (Hansen et al., 2013a). The required radiation time for the cylindrical reactor setup to remove $90 \%$ of the monochloramine from the pool sample was $4.2 \mathrm{~min}\left(2.1 \mathrm{~J} / \mathrm{cm}^{2}\right)$. In order to compare the experimental UV dose to a realistic treatment level, the UV system in the Gladsaxe swimming pool's hot water basin was used. This system consists of four UV lamps using a total of $2800 \mathrm{~W}$ and operating 24 hours per day on a total pool volume of $50 \mathrm{~m}^{3}$ (Kristensen et al., 2009). Therefore, the applied electrical energy dose from UV was $1.34 \mathrm{kWh} / \mathrm{m}^{3}$ per day, and so it can be calculated that the dose equivalent to one day of treatment is achieved after $9.5 \mathrm{~min}$ radiation $\left(4.7 \mathrm{~J} / \mathrm{cm}^{2}\right)$. Furthermore, using monochloramine as a second actinometer (Cheema et al., 2017), the UV dose was recalculated for our system to correspond to a 247 $\mathrm{mJ} / \mathrm{cm}^{2} \mathrm{UV}$ dose delivered per minute from a low pressure UV lamp, based on the data published in Li and Blatchley (2009).

\subsection{Chlorination}

The formation of DBPs as a result of chlorination was investigated using a standardised DBP formation assay. Similar tests have been used in other studies investigating the potential for the formation of $\mathrm{NCl}_{3}$ (Schmalz et al., 2011), THM and HAA in swimming pool water (Kanan, 2010), THM, HAN and HAA from synthetic body fluid (Hansen et al., 2012b) and particles from pools (Hansen et al., 2012a). The effect of chlorine concentration in the assay was also recently investigated by Hansen et al. (2013b). The concentration of free chlorine was adjusted to $3.0 \pm 0.05 \mathrm{mg} / \mathrm{L}$ by adding a sodium hypochlorite solution, and then the sample reacted for $24 \mathrm{~h}$ at $25^{\circ} \mathrm{C}$. Chlorination was performed in quadruplicate, with three samples used for DBP analysis and one for the determination of residual chlorine. Samples for DBP analysis were dosed with an ammonium chloride solution ( $50 \mathrm{mg} / \mathrm{L}$ ), to quench free chlorine, which neither affects the already formed DBP (Kristiana et al., 2014) nor increases N-DBP formation (Hua et al., 2014). The samples were extracted and analysed for DBPs the same day.

\subsection{Experiments}

In this study, batch experiments were performed in the laboratory to ensure controlled experimental conditions. The dark control samples were directly chlorinated for DBP analysis, to investigate the formation potential of pool water without UV treatment. These samples were passed through the UV reactor without UV light to ensure the same experimental conditions (retention time, stirring). All samples from three different pools were collected on the same day and used for experiments immediately upon arrival in the laboratory (within three hours of collection). Collected samples were divided into four equal subsamples from which the first subsample was used for initial analysis, second for dark control and third for treatment with a low UV dose and the fourth for a high UV dose. Samples were transferred into glass vials for analysis, without headspace.

\subsection{Calculation of parameters}

\subsubsection{Bromine incorporation}

Bromine incorporation was calculated as a percentage of the incorporated halogen, comprising bromine for each group of DBPs, by adding molar concentrations of each group species multiplied by the associated number of incorporated bromines divided by the total amount of incorporated halides. For example, the incorporation for THM was estimated by summing up threefold the molar concentration of bromoform, twofold the molar concentration of dibromochloromethane and the molar concentration of bromodichloromethane, which was then divided by three times the total THM. 


\subsubsection{Toxicity}

Toxicity was estimated as reported by Hansen et al. (2012b). Based on the measured concentration of the different DBPs, cytotoxicity and genotoxicity were estimated as the sum of the concentration of each compound divided by its $\mathrm{EC}_{50}$ (Equation (1)):

$$
\text { Toxicity }=\sum_{1}^{i} \frac{\mathrm{C}_{i}}{\mathrm{EC}_{50, i}}
$$

All EC 50 values were used as reported in the literature (Muellner et al., 2007; Plewa et al., 2008).

\section{Results and discussion}

To evaluate the effect of post-UV chlorination, samples were included in the investigation from three indoor chlorinated seawater pools. As batch experiments were conducted in a laboratory, the DBP formation may vary from continuous UV treatment carried out over a longer time scale. Furthermore, pool water does not receive doses equivalent to several days of treatment at once in a real treatment system, and thus there might be some reactions between chlorine and photolysis by-products for the first UV dose until water enters the UV reactor a second time.

Three classes of DBPs were investigated, including THMs (chloroform, bromodichloromethane, dibromochloromethane, and bromoform), HANs (dichloroacetonitrile, trichloroacetonitrile, bromochloroacetonitrile, dibromoacetonitrile) and HAAs (monochloroacetic acid, monobromoacetic acid, dichloroacetic acid, trichloroacetic acid, bromochloroacetic acid, dibromoacetic acid, bromodichloroacetic acid, dibromochloroacetic acid, tribromoacetic acid). However, some of the DBPs were not detected during the analysis, for example bromodichloromethane, dichloroacetonitrile, trichloroacetonitrile, monochloroacetic acid, monobromoacetic acid, dichloroacetic acid, trichloroacetic acid and bromodichloroacetic acid.

Water quality parameters from the three different pools sampled in this study are listed in Table 1 . These three pools are among pools studied in literature; Manasfi et al. (2016) found TOC values from 11 to 12 $\mathrm{mg} / \mathrm{L}$ (due to heavy use and high frequentation in summer) and Parinet et al. (2012) reported TOC values from 2.0 to $3.6 \mathrm{mg} / \mathrm{L}$ (due to lower frequentation in winter), this later being similar to our study (sampling in March). Furthermore, similar TOCs were reported by several studies on UV in freshwater pools, for example Cheema et al. (2017), $1.8 \mathrm{mg} / \mathrm{L}$; Cimetiere and De Laat. (2014), $2.75 \mathrm{mg} / \mathrm{L}$ and Spiliotopoulou et al. (2015), $2.1 \mathrm{mg} / \mathrm{L}$. Moreover, TOC concentration was not significantly affected by post-UV chlorination, as reported in previous studies of freshwater pools (Cheema et al., 2017; Spiliotopoulou et al., 2015), and so no further investigations were included in this study. Bromide content varied between 75 and $88.5 \mathrm{mg} / \mathrm{L}$ in the three pools, representing higher bromide content than found in the raw seawater used to fill these pools (72 mg/L). This discrepancy may be explained by the low frequency of water renewal, thereby leading to the upconcentration of bromide through water evaporation.

Table 1 . Water quality parameters

\begin{tabular}{lccc}
\hline Parameters & Pool-1 & Pool-2 & Pool-3 \\
\hline Temperature ( $\left.{ }^{\circ} \mathbf{C}\right)$ & 32.0 & 30.2 & 33.3 \\
pH & 8.13 & 8.07 & 8.22 \\
Conductivity (mS/cm) & 61.3 & 62.0 & 70.8 \\
Br $^{-}(\mathbf{m g} / \mathbf{L})$ & 88.5 & 75.0 & 78.3 \\
$\mathbf{O}_{\mathbf{2}}(\mathbf{\%})$ & 104 & 100 & 104 \\
TOC (mg/L) & 2.72 & 3.14 & 3.92 \\
Free chlorine (mg/L) & 0.57 & 0.52 & 0.91 \\
Total chlorine (mg/L) & 0.72 & 0.76 & 1.11 \\
\hline
\end{tabular}

\subsection{Chlorine consumption}

All treatments were analysed for residual chlorine after chlorination for $24 \mathrm{~h}$ (Fig 1). Low chlorine consumption was observed in dark control samples; however, it increased following UV treatment in all 
pools. Furthermore, the increase in chlorine consumption was proportional to consumption in the dark control samples for each pool, e.g. pool-1, high consumption in dark control and high increase in consumption by treatment; pool-2, lowest consumption in dark control and lowest increase in consumption by treatment and pool-3, highest consumption in dark control and highest increase in consumption after UV treatment. Moreover, high UV exposure resulted in high consumption in all pools, while chlorine consumption was higher in pool-3 compared to the other pools, most likely due to the higher TOC in this pool.

A likely explanation for the increase in chlorine consumption is that UV irradiation degraded organic matter in the pool samples to species more reactive to chlorine. A similar trend has been reported in freshwater pool studies (Cheema et al., 2017; Cimetiere and De Laat, 2014; Spiliotopoulou et al., 2015) and also in drinking water, where it has been observed that UV treatment increases the fraction of low molecular organic matter, which in turn increases chlorine consumption (Choi and Choi, 2010). Furthermore, hypobromous acid ( $\mathrm{HBrO})$ and hypobromite $\left(\mathrm{BrO}^{-}\right)$in seawater might be photolysed by $\mathrm{UV}$ radiation into hydroxyl $\left(\mathrm{HO}^{\circ}\right)$ and bromine radicals (Br*) (Feng et al., 2007; Watts and Linden, 2007), which then might react with organic matter present in the pool water. Thereby, non-chlorine reactive molecules may become highly reactive after UV treatment, thus leading to an observed increase in chlorine consumption. Nonetheless, in a recent study, increased chlorine reactivity caused by radical oxidation was found to be insignificant compared with the increase resulting from UV radiation (Spiliotopoulou et al., 2015).

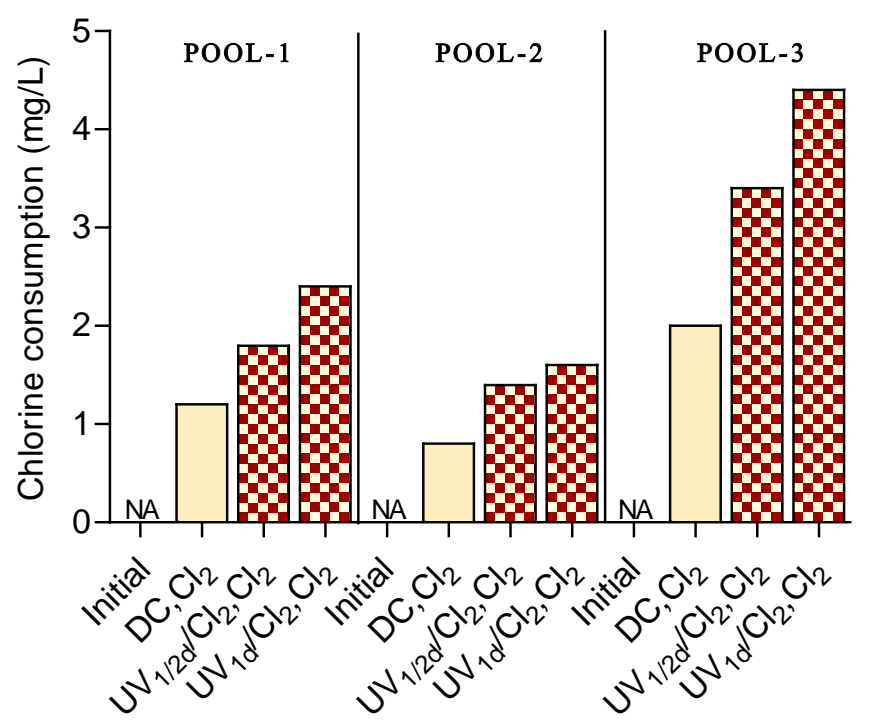

Figure 1 Chlorine consumption after $24 \mathrm{~h}$ at $25^{\circ} \mathrm{C}$. Three pool samples were investigated as pool-1, pool-2 and pool-3. 'DC',

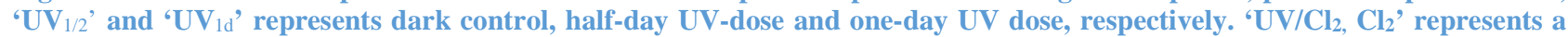
pre-chlorine-adjusted pool water sample treated with UV followed by chlorination. 'NA' is not applicable and indicates no incubation with chlorine, i.e. no consumption.

\subsection{Formation of DBPs in post-UV chlorination}

\subsubsection{Haloacetic acids (HAAs)}

Initial concentrations of HAA were higher in pool-2 compared with the other two pools (Figs. 2f, 2g, 2h, 2i). All pool water samples had formation potential for HAA, as increased concentrations were observed after chlorination for $24 \mathrm{~h}$. The highest formation potential (dark control) of HAA was observed in pool-3, which had the lowest initial HAA concentration, whereas the lowest formation potential (dark control) was noticed in the pool water (pool-2) with the highest initial HAA concentrations. The high increase in the formation potential (dark control) of pool-3 is likely due to the high TOC in this water. Furthermore, dibromoacetic acid and tribromoacetic acid were observed as predominant haloacetic acids, while bromochloroacetic acid and dibromochloroacetic acid were the sparsest of the detected compounds. 
The formation of total HAA (THAA) decreased in all pool water samples with post-UV chlorination (Fig 2). In fact, in pools 1 and 2, concentrations after UV treatment and chlorination were lower than the initial concentrations. The highest decrease (almost 60\%) was observed in pool-2, while the lowest decrease (20\%) was found in pool-1. Additionally, concentrations decreased further as a result of high UV exposure. However, concentration levels in pool-3 remained higher after treatment in relation to the initial concentration level.

Bromochloroacetic acid concentration remained unaffected by post-UV chlorination, while dibromoacetic acid and dibromochloroacetic acid concentrations decreased significantly. Dibromoacetic acid concentration decreased to a level of $10 \mu \mathrm{g} / \mathrm{L}$ and dibromochloroacetic acid to $1 \mu \mathrm{g} / \mathrm{L}$ in all pools. Furthermore, the highest decrease in concentration was observed in tribromoacetic acid by post-UV chlorination, where the concentration level decreased to the quantification limit.

Overall, concentrations of HAA decreased by post-UV chlorination, which is likely due to the direct photolysis of the HAA, as all HAA found in the pool water contained bromine, and bromine containing DBP in swimming pool water is generally easily photolysed by UV (Hansen et al., 2013a). Studies with other water types have also described that brominated HAA is photolysed by UV treatment (Jo et al., 2011).

\subsubsection{Trihalomethanes (THMs)}

Initial concentrations for THMs were higher in pool-2 compared with pool 1 and pool-3 (Figs. 2a, 2b, 2c). However, low formation potential (dark control) was observed in pool-1 and pool-3, while no formation potential (dark control) was noted in pool-2. Furthermore, bromoform was the most predominant THM followed by dibromochloromethane, whereas chloroform was the least prevalent in all pools.

Concentration increased for total THM (TTHM) with UV, followed by chlorination (Fig 2j). Furthermore, a low increase in concentration was observed in pool-2, while a high increase occurred in pool-1 and pool-3. Additionally, high UV exposure increased TTHM concentration further in all pools.

Bromoform and dibromochloromethane concentration increased following UV and chlorination treatment and increased further with high UV exposure. However, as chloroform concentrations were close to or under the quantification limit, no definite trend was observed for chloroform. Spiliotopoulou et al. (2015) reported that UV irradiation does not create chloroform in freshwater swimming pool waters, with or without free chlorine present, while Cassan et al. (2006), Cimetiere and De Laat (2014) and Spiliotopoulou et al. (2015) all reported chloroform formation as a result of chlorination following UV irradiation in freshwater pools. An increase in bromoform and in dibromochloromethane is quite surprising; indeed, previous studies have shown that both low and medium-pressure UV lamps are efficient to remove brominated THMs (Cimetiere and De Laat, 2014; Nicole et al., 1991). In the present case, the observed increase in the concentrations of these two THMs in post-chlorinated water suggests that the amount formed during post-chlorination was higher than the amount photo-decomposed in the UV reactor.

Overall, concentration increased for THMs with UV followed by chlorination. A possible explanation is that the breaking of large organic molecules, which increased the chlorine reactivity of dissolved organic matter, also promoted precursors in the pool water for THM formation. Previous studies on freshwater pools have also reported similar trends regarding an increase in THM concentration through UV irradiation (Cimetiere and De Laat, 2014). However, Spiliotopoulou et al. (2015) reported that UV treatment accelerates THM formation instead of increasing it, since pool water without UV treatment had the same increase in THM formation with a high chlorine level. The study also reported that THM concentration decreased with high UV dose treatment followed by chlorination which was likely due to photodegradation of THM and their precursors at high UV dose. Moreover, Cheema et al. (2017) also reported a decrease in THM concentration with high UV dose treatment followed by chlorination which was likely due to decrease in TOC level by oxidation at high UV dose and hence less amount of precursors were available for DBP formation. Therefore, it is likely that repeating UV treatment followed by chlorination in cycles with even lower doses might decrease the formation of THM and their precursors in seawater pools. 


\subsubsection{Haloacetonitriles (HANs)}

Initial concentrations were similar for HANs in all pools (Figs. 2d, 2e), and no formation potential (dark control) for HANs was observed in the pool water. Furthermore, dibromoacetonitrile was the main HAN, followed by bromochloroacetonitrile.

Concentrations increased for total HANs with UV, followed by chlorination (Fig 2k). Furthermore, a high increase was observed in pool-3, while lower increases were observed in pool-1 and pool-2. However, high UV exposure had no significant effect on concentrations. Bromochloroacetonitrile concentration increased to a similar level in all pools with UV, followed by chlorination, whereas a high increase in dibromoacetonitrile concentration was observed in pool-3 and lower increases in pool-1 and pool-2.

HANs are the most toxic group investigated in this study (Plewa et al., 2008) and have also been reported as contributing most in terms of toxicity to chlorinated pool water (Kramer et al., 2009). Cimetiere and De Laat (2014) reported an increase in the concentration of dichloroacetonitrile and bromochloroacetonitrile via the post-UV chlorination of freshwater pools, which is similar to the findings in this study in relation to seawater pools. However, a recent study has reported HANs degradation in freshwater pools with UV treatment by repeating experiments in cycles (Cheema et al., 2017). 

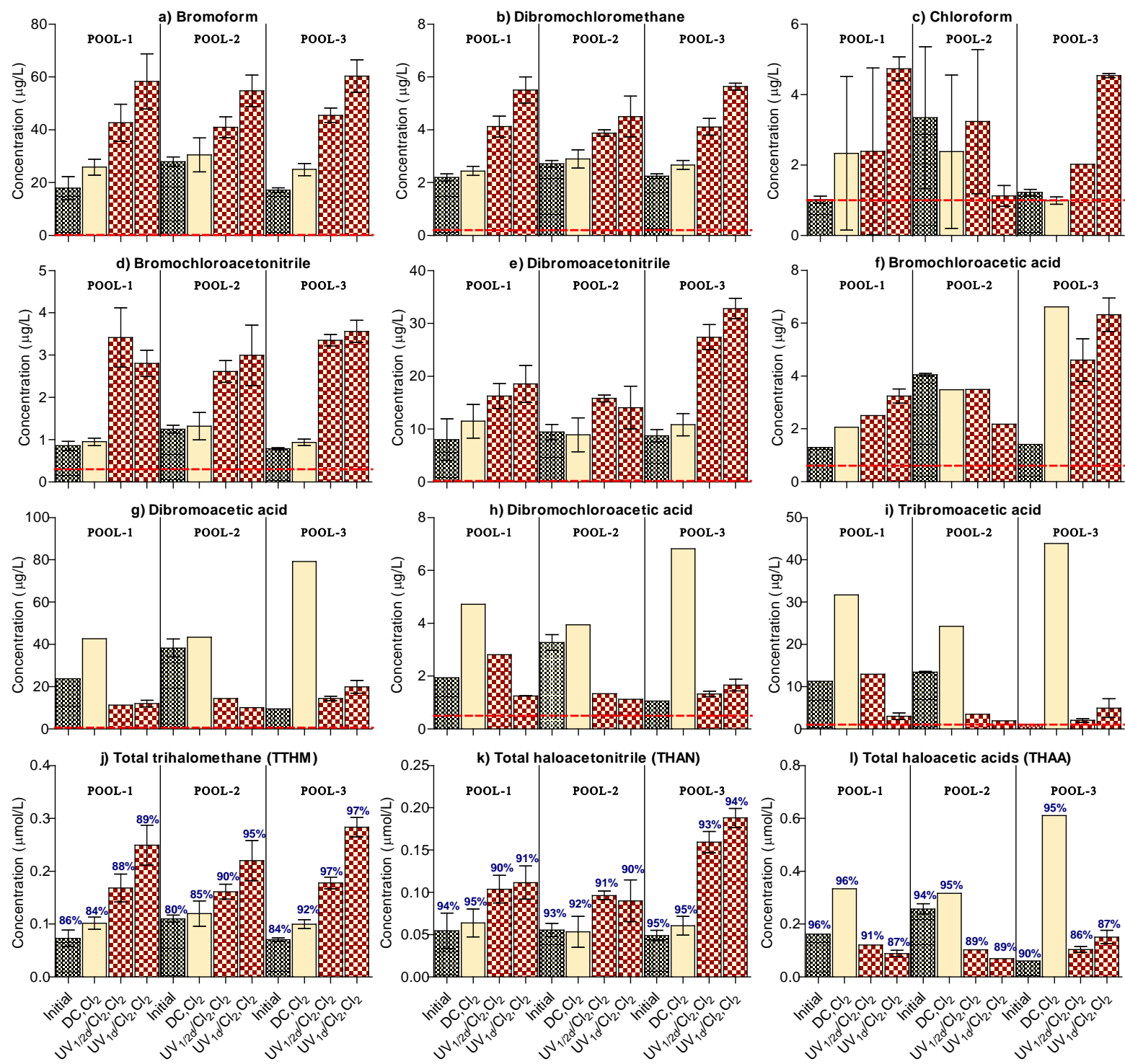

Figure 2. Concentration of investigated DBPs in different experimental conditions for samples from three different pools, where a), b) and c) represent THMs; d) and e) represent HANs; f), g), e) and h) represent HAAs and j), k) and l) represent total THM, total HAN and total HAA, respectively. All treatments are followed by post-chlorination except for the initial analysis. The error bars represent the standard deviation of three replicates. Percentage (\%) indicates the amount of bromine incorporation. The dotted line indicates the limit of quantification (LOQ), and error bars are standard deviation among replicates.

\subsection{Bromine incorporation}

Spiliotopoulou et al. (2015) reported bromine substitution shifted from the larger brominated molecules to smaller volatile compounds via UV treatment, followed by the chlorination of freshwater pool waters, which resulted in increased bromine substitution in THM. However, bromine incorporation was expected to be unaffected by UV treatment followed by the chlorination of water from seawater pools, due to the presence of high bromide levels of seawater in this study. Furthermore, previous studies with drinking water have shown increased DBP levels in the presence of bromide, as well as the formation of brominated DBPs (Chang et al., 2001; Hua et al., 2006), which is likely due to the oxidation of bromide by hypochlorous acid to form hypobromous acid (White, 1992), the latter of which reacts with the dissolved organic matter and forms brominated DBPs. A higher level of brominated DBPs has been reported by several studies for pools filled with seawater (Chowdhury et al., 2014; Manasfi et al., 2016). Therefore, increased bromide levels in 
seawater pool can increase concentrations of brominated DBPs, which in turn can increase health risks to swimmers. Bromine incorporation was estimated before and after treatment to evaluate the effect of UV treatment on DBP formation in the seawater pool.

THM concentration increased, as bromine incorporation increased by post-UV chlorination. Furthermore, HAN concentration increased, while bromine substitution levels decreased with UV followed by chlorination. However, HAA concentration significantly decreased, as bromine incorporation decreased with UV treatment followed by chlorination. Overall, the bromine incorporation level goes up and down in a single treatment but is expected to decrease after multiple or continuous UV treatments.

\subsection{Predicted toxicity}

Seawater contains high concentrations of bromide which resulted in a high fraction of brominated DBPs that are generally more toxic than their chlorinated analogs (Muellner et al., 2007; Plewa et al., 2008). Cytotoxicity and genotoxicity were estimated to evaluate the effect of DBPs formation on bather's health (Fig 3a, 3b). Although brominated DBPs were detected for all the investigated groups (Fig S3, SI), the HANs had the highest contribution to the overall toxicity (Table S2, SI).

Potential health effects of swimming pool water have been reported by previous studies of freshwater pools. Villanueva et al. (2007) reported increased bladder cancer risk after swimming in freshwater pools, whilst Liviac et al. (2010) reported the higher genotoxicity of freshwater pools in comparison to supply water, due to DBP formation in the pool water. Furthermore, DBP regulations in swimming pool water have mostly focused only on THMs and chloramines around the world. However, previous studies have shown that other DBPs, such as HANs, HAAs and cyanogen halides, are generally more toxic than regulated DBPs (Glauner et al., 2005; Zwiener et al., 2007). Therefore, in order to evaluate the effect of DBP formation on swimmers' health, the cytotoxicity and genotoxicity of DBPs were estimated as described in the materials and method section, using Equation 1.

The calculated initial cytotoxicity was lower in pool-3 than in pool-1 and pool-2 (Fig. 3a). In general, the cytotoxicity increased in the chlorinated samples (dark control) expect for pool-2 where it was unchanged. The cytotoxicity was further increased in the samples which were UV treated and chlorinated and the highest calculated cytotoxicity was found for pool-3. Furthermore, HANs contributed most to toxicity, followed by HAAs and with THMs contributing the least. Calculated genotoxicity (Fig. 3b) followed similar trends as cytotoxicity where increased genotoxicity was found in UV treated and chlorinated samples compared with the initial samples. The HANs had the highest contribution to the calculated genotoxicity and HAAs only had a minor contribution. The THMs did not contribute to calculated genotoxicity as they are not genotoxic (Muellner et al., 2007; Plewa et al., 2008).

Overall, HANs were the main toxicity contributor and most potent DBP group investigated in this study. A previous study on freshwater pools also reported HANs higher potency of cytotoxicity and genotoxicity than HAAs and THMs (Plewa et al., 2008). Furthermore, Kramer et al. (2009) reported that two HANs, dibromoacetonitrile and bromochloroacetonitrile, were the main contributors to the overall toxicity of pool water in freshwater pools. However, a recent study reported HANs degradation in freshwater pools following repeated UV treatment (Cheema et al., 2017). As this study was conducted in a single time batch experiment, it is likely that the toxicity would indeed decrease in seawater pools following repeated or continuous UV treatment. 

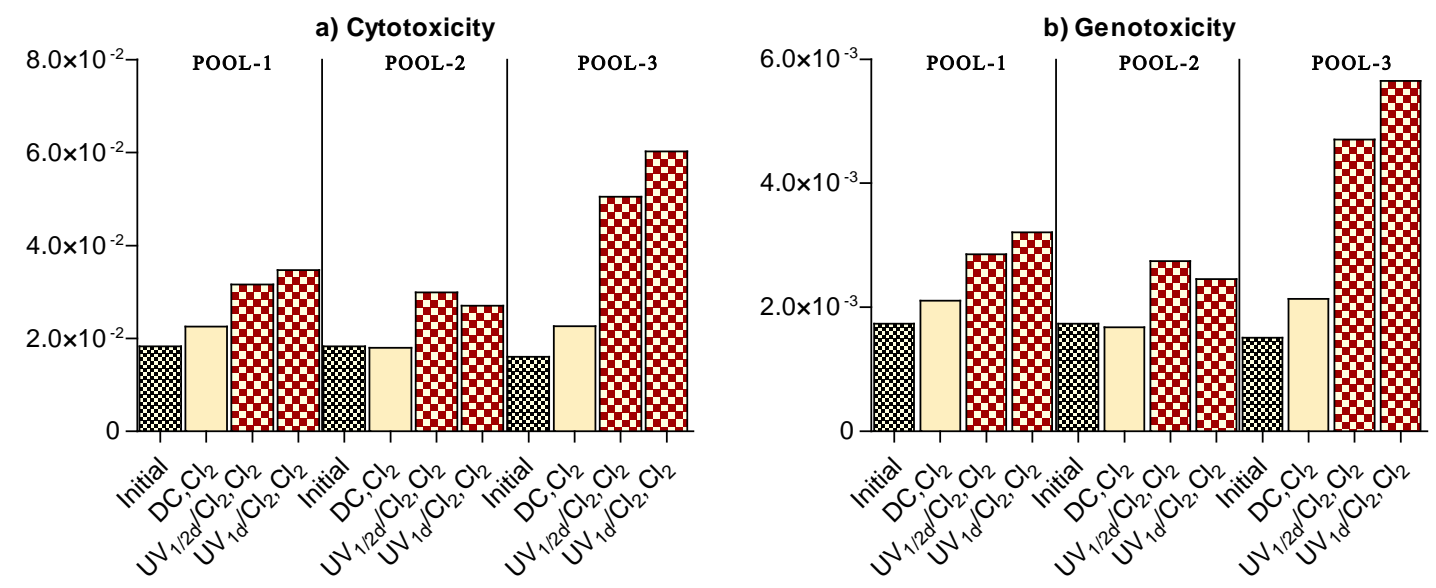

Figure 3. Toxicity estimation for disinfection by-products at different experimental conditions from three seawater pools. a) and b) are estimated cytotoxicity and genotoxicity, respectively.

\section{Conclusions}

The present study is the first to investigate the fate of brominated DBPs, submitted to a medium-pressure UV lamp followed by post-chlorination, in real seawater swimming pool samples. The results show that UV followed by chlorination does not lead to real abatement in most of the DBPs. Concentration of HAA i.e. dibromoacetic acid and dibromochloroacetic acid significantly decreased while concentration of THM i.e. bromoform and dibromochloromethane and concentration of HAN i.e. bromochloacetonitrile and dibromoacetonitrile increased with UV followed by chlorination. Moreover, as HAN were the main contributor to the estimated toxicity thus the toxicity increased with UV treatment followed by chlorination. Therefore, this study suggests that UV treatment used for dechloramination could result in increased formation of some brominated DBPs in seawater swimming pools. Further studies would be required to interpret these findings including the influence of water composition, UV dose rate and chlorine dose on the kinetics of brominated DBP formation. Another key factor to investigate in the follow up experiments is the effect of repeated treatments which could reduce TOC level and most importantly, the concentration of DBPs in seawater pools.

\section{Acknowledgements}

The authors would like to thank the public pools' staff for their cooperation. Waqas A. Cheema is thankful to National University of Sciences \& Technology (NUST) and Technical University of Denmark (DTU) for their cooperation and support of this work.

\section{References}

Bougeard, C.M.M., Goslan, E.H., Jefferson, B., Parsons, S.A., 2010. Comparison of the disinfection byproduct formation potential of treated waters exposed to chlorine and monochloramine. Water Res. 44, 729-740. doi:10.1016/j.watres.2009.10.008

Cassan, D., Mercier, B., Castex, F., Rambaud, A., 2006. Effects of medium-pressure UV lamps radiation on water quality in a chlorinated indoor swimming pool. Chemosphere 62, 1507-1513. doi:10.1016/j.chemosphere.2005.06.006

Chang, E.E., Lin, Y.P., Chiang, P.C., 2001. Effects of bromide on the formation of THMs and HAAs. Chemosphere 43, 1029-1034. doi:10.1016/S0045-6535(00)00210-1

Charlier, R.H., Chaineux, M.-C.P., 2009. The Healing Sea: A Sustainable Coastal Ocean Resource: Thalassotherapy. J. Coast. Res. 254, 838-856. doi:10.2112/08A-0008.1 
Cheema, W.A., Kaarsholm, K.M.S., Andersen, H.R., 2017. Combined UV treatment and ozonation for the removal of by-product precursors in swimming pool water. Water Res. 110, 141-149. doi:org/10.1016/j.watres.2016.12.008

Choi, Y., Choi, Y.-J., 2010. The effects of UV disinfection on drinking water quality in distribution systems. Water Res. 44, 115-122. doi:10.1016/j.watres.2009.09.011

Chowdhury, S., Alhooshani, K., Karanfil, T., 2014. Disinfection byproducts in swimming pool: Occurrences, implications and future needs. Water Res. 53, 68-109. doi:10.1016/j.watres.2014.01.017

Cimetiere, N., De Laat, J., 2014. Effects of UV-dechloramination of swimming pool water on the formation of disinfection by-products: A lab-scale study. Microchem. J. 112, 34-41. doi:10.1016/j.microc.2013.09.014

Crecente, J.M., Santé, I., Díaz, C., Crecente, R., 2012. A multicriteria approach to support the location of thalassotherapy (seawater therapy) resorts: Application to Galicia region, NW Spain. Landsc. Urban Plan. 104, 135-147. doi:10.1016/j.landurbplan.2011.10.010

Domino, M.M., Pepich, B. V., Munch, D.J., Fair, P.S., Xie, Y., 2003. Method 552.3 Determination of haloacetic acids and dalapon in drinking water by liquid-liquid microextraction, derivatization, and gas chromatography with electron capture detection. Environ. Prot. Agency, Cincinnati, OH.

Feistel, R., Weinreben, S., Wolf, H., Seitz, S., Spitzer, P., Adel, B., Nausch, G., Schneider, B., Wright, D.G., 2009. Density and Absolute Salinity of the Baltic Sea 2006-2009. Ocean Sci. Discuss. 6, 1757-1817. doi:10.5194/osd-6-1757-2009

Feng, Y., Smith, D.W., Bolton, J.R., 2007. Photolysis of aqueous free chlorine species (HOCl and OCl-) with 254 nm ultraviolet light. J. Environ. Eng. Sci. 6, 277-284. doi:10.1139/S06-052

Ged, E.C., Boyer, T.H., 2014. Effect of seawater intrusion on formation of bromine-containing trihalomethanes and haloacetic acids during chlorination. Desalination 345, 85-93. doi:10.1016/j.desal.2014.04.021

Glauner, T., Kunz, F., Zwiener, C., Frimmel, F.H., 2005. Elimination of swimming pool water disinfection by-products with advanced oxidation processes (AOPs). Acta Hydrochim. Hydrobiol. 33, 585-594.

Guglielmina, F., Righi, E., Predieri, G., Giacobazzi, P., Mastroianni, K., Aggazzotti, G., 2010. Prevalence of ocular, respiratory and cutaneous symptoms in indoor swimming pool workers and exposure to disinfection by-products (DBPs). Int. J. Environ. Res. Public Health 7, 1379-1391. doi:10.3390/ijerph7041379

Hansen, K.M.S., Willach, S., Mosbæk, H., Andersen, H.R., 2012a. Particles in swimming pool filters - does pH determine the DBP formation? Chemosphere 87, 241-247. doi:10.1016/j.chemosphere.2012.01.003

Hansen, K.M.S., Willach, S., Antoniou, M.G., Mosbæk, H., Albrechtsen, H.J., Andersen, H.R., 2012b. Effect of $\mathrm{pH}$ on the formation of disinfection byproducts in swimming pool water - Is less THM better? Water Res. 46, 6399-6409. doi:10.1016/j.watres.2012.09.008

Hansen, K.M.S., Zortea, R., Piketty, A., Vega, S.R., Andersen, H.R., 2013a. Photolytic removal of DBPs by medium pressure UV in swimming pool water. Sci. Total Environ. 443, 850-856. doi:10.1016/j.scitotenv.2012.11.064

Hansen, K.M.S., Albrechtsen, H.-J., Andersen, H.R., 2013b. Optimal pH in chlorinated swimming pools balancing formation of by-products. J. Water Health 11, 465-472. doi:10.2166/wh.2013.156

Hinckley, A.F., Bachand, A.M., Reif, J.S., 2005. Late pregnancy exposures to disinfection by-products and growth-related birth outcomes. Environ. Health Perspect. 113, 1808-1813. doi:10.1289/ehp.8282 
Hua, G., Kim, J., Reckhow, D.A., 2014. Disinfection byproduct formation from lignin precursors. Water Res. 63, 285-295. doi:10.1016/j.watres.2014.06.029

Hua, G., Reckhow, D.A., Kim, J., 2006. Effect of Bromide and Iodide Ions on the Formation and Speciation of Disinfection Byproducts during Chlorination. Environ. Sci. Technol. 40, 3050-3056. doi:10.1021/es0519278

Jo, C.H., Dietrich, A.M., Tanko, J.M., 2011. Simultaneous degradation of disinfection byproducts and earthy-musty odorants by the UV/H2O2 advanced oxidation process. Water Res. 45, 2507-2516. doi:10.1016/j.watres.2011.02.006

Kanan, A., 2010. Occurrence and formation of disinfection by-products in indoor swimming pools water. Clemson University.

Kramer, M., Hübner, I., Rörden, O., Schmidt, C.K., 2009. Haloacetonitriles - another importent group of disinfection byproducts in swimming pool water., in: Swimming Pool \& Spa International Conference. London, UK.

Kristensen, G.H., Klausen, M.M., Andersen, H.R., 2010. Testing of different treatment technologies in swimming pools (In Danish: Afprøvning af forskellige renseteknologier på svommebade). Danish Nature Agency, Denmark. http://www.naturstyrelsen.dk/.

Kristensen, G.H., Klausen, M.M., Andersen, H.R., Erdinger, L., Lauritsen, F.R., Arvin, E., Albrechtsen, H.J., 2009. Full scale test of UV-based water treatment technologies at Gladsaxe Sportcentre - with and without advanced oxidation mechanisms, in: The Third International Swimming Pool and Spa Conference, London, March.

Kristiana, I., Lethorn, A., Joll, C., Heitz, A., 2014. To add or not to add: The use of quenching agents for the analysis of disinfection by-products in water samples. Water Res. 59, 90-98. doi:10.1016/j.watres.2014.04.006

Lee, K.-H., Lee, T.J., 2015. Opportunities and Issues in the Health Tourism Industry: Deep Sea Water Development in Taiwan. Tour. Anal. 20, 419-424. doi:10.3727/108354215X14400815080569

Li, J., Blatchley III, E.R., 2009. UV photodegradation of inorganic chloramines. Environ. Sci. Technol. 43, 60-65. doi:10.1021/es8016304

Liviac, D., Wagner, E.D., Mitch, W.A., Altonji, M.J., Plewa, M.J., 2010. Genotoxicity of water concentrates from recreational pools after various disinfection methods. Environ. Sci. Technol. 44, 3527-3532.

Manasfi, T., Coulomb, B., Boudenne, J.-L., 2017a. Occurrence, origin and toxicity of disinfection byproducts in chlorinated swimming pools: An overview. Int. J. Hyg. Environ. Health 1-13. doi:10.1016/j.ijheh.2017.01.005

Manasfi, T., De Méo, M., Coulomb, B., Di Giorgio, C., Boudenne, J.L., 2016. Identification of disinfection by-products in freshwater and seawater swimming pools and evaluation of genotoxicity. Environ. Int. 88, 94-102. doi:10.1016/j.envint.2015.12.028

Manasfi, T., Méo, M. De, Di, C., Coulomb, B., Boudenne, J., 2017b. Assessing the genotoxicity of two commonly occurring byproducts of water disinfection: Chloral hydrate and bromal hydrate. Mutat. Res. - Genet. Toxicol. Environ. Mutagen. 813, 37-44. doi:10.1016/j.mrgentox.2016.11.009

Muellner, M.G., Wagner, E.D., Mccalla, K., Richardson, S.D., Woo, Y.T., Plewa, M.J., 2007. Haloacetonitriles vs. regulated haloacetic acids: Are nitrogen-containing DBFs more toxic? Environ. Sci. Technol. 41, 645-651. doi:10.1021/es0617441

Munch, D.J., Hautman, D.P., 1995. Determination of Chlorination Disinfection Byproducts, Chlorinated Solvents, and Halogenated Pesticides/Herbicides in Drinking Water by Liquid-Liquid Extraction and 
Gas Chromatography With Electron-Capture Detection-Method 551.1. U.S. Environ. Prot. Agentcy.

Nicole, I., De Laat, J., Dore, M., Duguet, J.P., Suty, H., 1991. Etude de la degradation des trihalomethanes en milieu aqueux dilue par irradiation UV - determination du rendement quantique de photolyse a 253,7 nm. Environ. Technol. 12, 21-31. doi:10.1080/09593339109384978

Parinet, J., Tabaries, S., Coulomb, B., Vassalo, L., Boudenne, J.L., 2012. Exposure levels to brominated compounds in seawater swimming pools treated with chlorine. Water Res. 46, 828-836. doi:10.1016/j.watres.2011.11.060

Plewa, M.J., Wagner, E.D., Metz, D.H., Kashinkunti, R., Jamriska, K.J., Meyer, M., 2012. Differential toxicity of drinking water disinfected with combinations of ultraviolet radiation and chlorine. Environ. Sci. Technol. 46, 7811-7817. doi:10.1021/es300859t

Plewa, M.J., Wagner, E.D., Muellner, M.G., Hsu, K.M., Richardson, S.D., 2008. Comparative mammalian cell toxicity of N-DBPs and C-DBPs, in: Karanfil, T., SW, K., Xie, Y. (Eds.), Disinfection By-Products in Drinking Water: Occurrence, Formation, Helth Effects, and Control, Acs Symposium Series. American Chemical Society, Washington, DC, pp. 36-50.

Richardson, S.D., DeMarini, D.M., Kogevinas, M., Fernandez, P., Marco, E., Lourencetti, C., Ballesté, C., Heederik, D., Meliefste, K., McKague, A.B.B., Marcos, R., Font-Ribera, L., Grimalt, J.O., Villanueva, C.M., 2010. What's in the pool? A comprehensive identification of disinfection by-products and assessment of mutagenicity of chlorinated and brominated swimming pool water. Environ. Health Perspect. 118, 1523-1530. doi:10.1289/ehp.1001965

Richardson, S.D., Plewa, M.J., Wagner, E.D., Schoeny, R., DeMarini, D.M., 2007. Occurrence, genotoxicity, and carcinogenicity of regulated and emerging disinfection by-products in drinking water: A review and roadmap for research. Mutat. Res. - Rev. Mutat. Res. 636, 178-242. doi:10.1016/j.mrrev.2007.09.001

Salameh, E., Tarawneh, A., Al-Raggad, M., 2016. Origin of high bromide concentration in the water sources in Jordan and in the Dead Sea water. Arab. J. Geosci. 9, 414. doi:10.1007/s12517-016-2431-9

Schmalz, C., Frimmel, F.H., Zwiener, C., 2011. Trichloramine in swimming pools - Formation and mass transfer. Water Res. 45, 2681-2690. doi:10.1016/j.watres.2011.02.024

Shani, J., Sulliman, A., Katzir, I., Brenner, S., 1995. Penetration of selected Dead Sea minerals through a healthy rabbit skin, from a sustained-release transparent varnish, as a prospective treatment for psoriasis. J. Eur. Acad. Dermatology Venereol. 4, 267-272. doi:10.1111/j.1468-3083.1995.tb00349.x

Spiliotopoulou, A., Hansen, K.M.S., Andersen, H.R., 2015. Secondary formation of disinfection by-products by UV treatment of swimming pool water. Sci. Total Environ. 520, 96-105. doi:10.1016/j.scitotenv.2015.03.044

Summerhayes, C.P. (Colin P., Thorpe, S.A. (Stephen A.., 1996. Oceanography : an illustrated guide. Manson.

Teo, T.L.L., Coleman, H.M., Khan, S.J., 2015. Chemical contaminants in swimming pools: Occurrence, implications and control. Environ. Int. 76, 16-31. doi:10.1016/j.envint.2014.11.012

Villanueva, C.M., Cantor, K.P., Grimalt, J.O., Malats, N., Silverman, D., Tardon, A., Garcia-Closas, R., Serra, C., Carrato, A., Castaño-Vinyals, G., Marcos, R., Rothman, N., Real, F.X., Dosemeci, M., Kogevinas, M., 2007. Bladder cancer and exposure to water disinfection by-products through ingestion, bathing, showering, and swimming in pools. Am. J. Epidemiol. 165, 148-156. doi:10.1093/aje/kwj364

Wang, K., Guo, J., Yang, M., Junji, H., Deng, R., 2009. Decomposition of two haloacetic acids in water using UV radiation, ozone and advanced oxidation processes. J. Hazard. Mater. 162, 1243-1248. doi:10.1016/j.jhazmat.2008.06.012 
Wang, W., Qian, Y., Boyd, J.M., Wu, M., Hrudey, S.E., Li, X.F., 2013. Halobenzoquinones in swimming pool waters and their formation from personal care products. Environ. Sci. Technol. 47, 3275-3282. doi:10.1021/es304938x

Watts, M.J., Linden, K.G., 2007. Chlorine photolysis and subsequent OH radical production during UV treatment of chlorinated water. Water Res. 41, 2871-2878. doi:10.1016/j.watres.2007.03.032

White, G.C., 1992. Handbook of chlorination and alternative disinfectants. Van Nostrand Reinhold, New York.

WHO, 2006. Guidelines for safe recreational water environments. Volume 2, Swimming pools and similar environments. World Health Organization, WHO Press, Geneva, Switzerland.

Wyer, M.D., Wyn-Jones, A.P., Kay, D., Au-Yeung, H.-K.C., Gironés, R., López-Pila, J., de Roda Husman, A.M., Rutjes, S., Schneider, O., 2012. Relationships between human adenoviruses and faecal indicator organisms in European recreational waters. Water Res. 46, 4130-4141. doi:10.1016/j.watres.2012.04.008

Zare Afifi, M., Blatchley, E.R., 2016. Effects of UV-based treatment on volatile disinfection byproducts in a chlorinated, indoor swimming pool. Water Res. 105, 167-177. doi:10.1016/j.watres.2016.08.064

Zwiener, C., Richardson, S.D., DeMarini, D.M., Grummt, T., Glauner, T., Frimmel, F.H., 2007. Drowning in disinfection byproducts? Assessing swimming pool water. Environ. Sci. Technol. 41, 363-372. 